\title{
Investigation on Effects of Chain Extenders and Cross-linking Agents of Polyurethane Elastomers Using Independent Building Vibration Isolation Sensor
}

\author{
Taijiang Gui, ${ }^{1}$ Tianqi Xia, ${ }^{2}$ Hao Wei, ${ }^{2}$ Zhijia Zhang, ${ }^{2 *}$ and Xiao Ouyang ${ }^{2 * *}$ \\ ${ }^{1}$ State Key Laboratory of Marine Coatings, Marine Chemical Research Institute Co., Ltd., \\ Qingdao Shandong 266071, China \\ ${ }^{2}$ Key Laboratory of Superlight Material and Surface Technology of Ministry of Education, \\ College of Material Science and Chemical Engineering, \\ Harbin Engineering University, Harbin 150001, China
}

(Received May 5, 2019; accepted August 29, 2019)

Keywords: polyurethane elastomers, vibration isolation sensor, chain extenders, cross-linking agents

Polymeric materials are used for vibration protection owing to their high-energy dissipation or adsorption. In this study, polyurethane elastomers (PUEs) were prepared using six kinds of chain extender and three types of cross-linking agent. The relationships between their structures and vibration isolation performances were investigated in detail using an independent building vibration isolation sensor. The results showed that elastomers with fewer main chain carbon atoms exhibited better vibration isolation performance. With increasing number of side groups of the chain extender, both the damping and vibration isolation properties were improved. For different cross-linkers, a more irregular structure of the cross-linkers resulted in the better vibration isolation performance of the PUEs.

\section{Introduction}

Vibration is a universal physical phenomenon, such as the beating of the heart and the vibration of the vocal cords when speaking. Negative effects of vibration on people, machine, and devices are well known. ${ }^{(1,2)}$ The best solution is to eliminate the vibration of the vibration source. However, this is almost impossible to achieve. To reduce adverse effects and control the vibration, one of the most feasible methods is to minimize the vibration transmission between the source and the receiver. Metallic and polymeric materials are both used for vibration protection. Nevertheless, for systems that function at or near resonance, damping elements with as high-energy dissipation (adsorption) as possible are necessary. In such applications, polymeric materials are the only option. ${ }^{(3,4)}$

Polyurethanes are a class of versatile macromolecules with extraordinary and versatile performances, including excellent elasticity, flexibility, a wide range of hardness, high tearing capacity, good abrasion resistance, and processability. ${ }^{(5-8)}$ There is high interest in their

\footnotetext{
*Corresponding author: e-mail: zhijia.zhang@hrbeu.edu.cn

** Corresponding author: e-mail: oyx1028@hrbeu.edu.cn

https://doi.org/10.18494/SAM.2019.2424
} 
applications as coatings, ${ }^{(9,10)}$ adhesives, ${ }^{(11,12)}$ air filters,${ }^{(13,14)}$ protective textiles, ${ }^{(15,16)}$ and sensors. ${ }^{17,18)}$ Polyurethane elastomers (PUEs) have a special microphase separation structure, which has shown excellent performance ${ }^{(19)}$ and has attracted the interest of researchers for use in damping and vibration isolation. ${ }^{(20-22)}$ However, the performance analysis of vibration isolation has mainly been by software simulations. ${ }^{(23-26)}$ Moreover, no detailed information has been reported on the relationship between the internal structure of PUEs and their vibration isolation characteristics.

As reported in this article, we designed a series of PUEs with different chain extenders and cross-linking agents. The relationships between their structures and vibration isolation performances were investigated using independent building vibration isolation equipment. The effect of the chain extenders on their performance was explored, focusing on the main-chain length and the number of side groups of the chain extender. The macroisolation performance for the different types of cross-linking agents of the PUEs was also investigated.

\section{Materials and Methods}

\subsection{Materials}

Methylenebis-(phenylisocyanate) (MDI), poly(propylene glycol)-2000 (PPG-2000), ethylene glycol (EG), 1,3-propanediol (PDO), 1,4-butanediol (BDO), 1,6-hexanediol (HDO), 2-methyl1,3-propanediol (MPO), neopentyl glycol (NPG), 1,2,6-hexanetriol (HTO), glycerol (GLY), and triethanolamine (TEA) were purchased from Aladdin (Shanghai China). All reagents were used as received without any further purification.

\subsection{Preparation of prepolymer}

A certain amount of PPG-2000 was sealed in a reaction kettle using high-vacuum silicone grease. The reaction kettle was placed in a vacuum oven at $120^{\circ} \mathrm{C}$ for $2 \mathrm{~h}$ to induce dehydration while the pump pressure was maintained from 0.085 to $0.095 \mathrm{MPa}$. The temperature was decreased to $50{ }^{\circ} \mathrm{C}$ when the content of water was below $0.05 \%$. A certain mass of MDI was then mixed with the PPG-2000. The temperature was kept at $50{ }^{\circ} \mathrm{C}$ for $1 \mathrm{~h}$ and then increased to $80^{\circ} \mathrm{C}$ for $2 \mathrm{~h}$ under a $\mathrm{N}_{2}$ atmosphere. The prepolymer was stored in a cool and dry environment.

\subsection{Preparation of PUEs}

The prepolymer was heated for $20 \mathrm{~min}$ at $70{ }^{\circ} \mathrm{C}$. Then the chain extender and cross-linking agent were mixed and placed in a vacuum oven at room temperature to induce defoaming. The sample was then poured into a metal mold coated with a demolding agent. The sample was then solidified at a temperature of $120^{\circ} \mathrm{C}$ for $24 \mathrm{~h}$. The PUEs were tested after 7 days at room temperature. The formulas of the raw materials for the PUEs are shown in Fig. 1. 


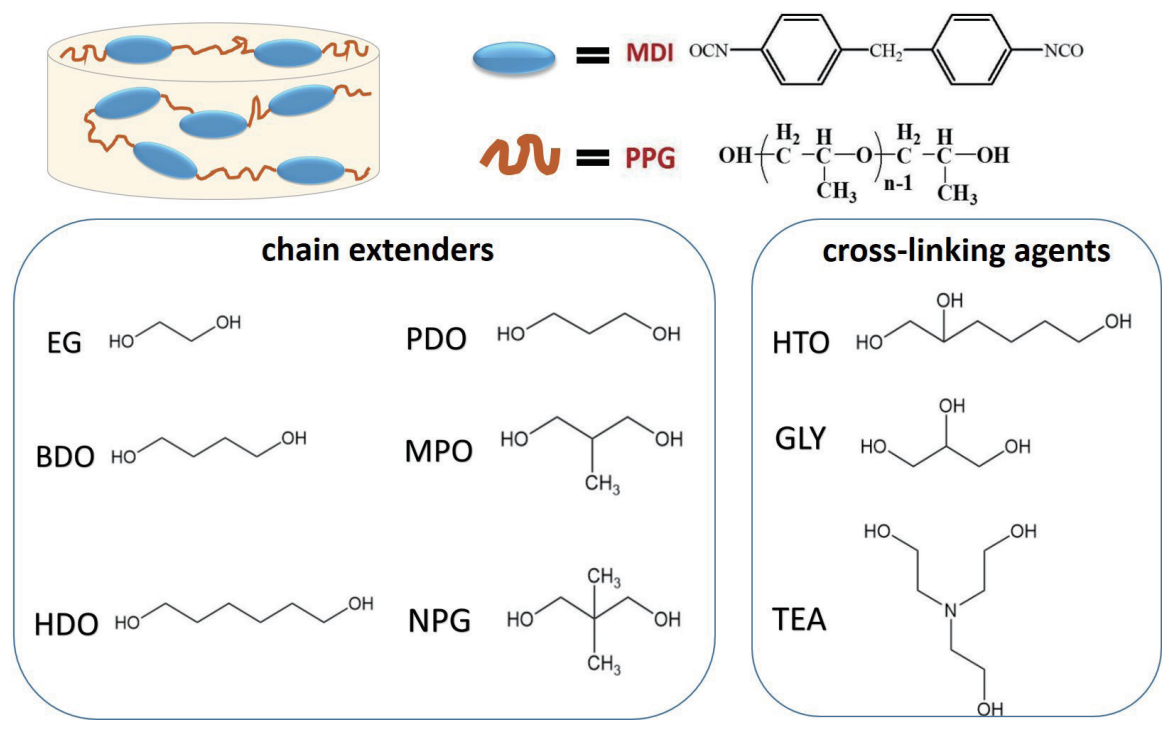

Fig. 1. (Color online) Formulas of raw materials for PUEs.

\subsection{Characterizations}

Fourier transform infrared (FT-IR) spectra were collected using a Thermo Scientific Nicolet iS10 spectrophotometer. Dynamic mechanical analysis (DMA) was performed using a Q-800 instrument (TA Instruments, USA) in the stretching mode under a $\mathrm{N}_{2}$ atmosphere.

\subsection{Evaluation of vibration isolation performance}

The vibration isolation sensor equipment is shown in Fig. 2. The vibration isolation performance of the PUEs was evaluated by the difference in vibration levels between the excitation forces at the input and output ends of the material. The sweep range of the frequency was $150-800 \mathrm{~Hz}$.

\section{Results and Discussion}

\subsection{FT-IR analysis}

Chain extenders affect the length of hard segment molecular chains and the morphology of hard-segment accumulation. To determine the effect of different chain extenders on vibration transfer performance, EG, BDO, HDO, PDO, MPO, and NPG were used to prepare the PUEs. The PUEs with different chain extenders were named EG-PU, BDO-PU, HDO-PU, PDO-PU, MPO-PU, and NPG-PU, respectively. Cross-linking agents, which are an important component of PUEs, determine the structure and density of the cross-linking network. To study the effect of cross-linking agents on vibration transfer performance, TEA, HTO, and GLY were investigated as cross-linking agents, and the PUEs with these cross-linking agents were named 

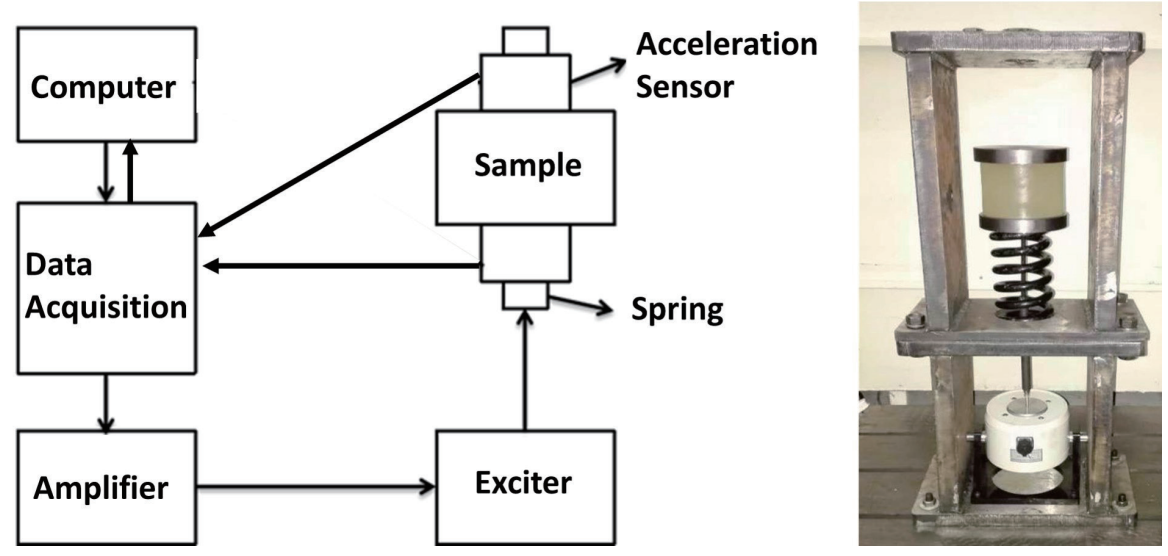

Fig. 2. (Color online) Scheme and photograph of vibration isolation sensor equipment.

Table 1

Formulations of PUEs.

\begin{tabular}{lccccccc}
\hline Sample & \multicolumn{2}{c}{ Prepolymer } & $\begin{array}{c}\text { Chain } \\
\text { extender }\end{array}$ & $\begin{array}{c}\text { Cross-linking } \\
\text { agent }\end{array}$ & $A_{1700}$ & $A_{1730}$ & HBA \\
\hline EG-PU & MDI & PPG-2000 & EG & TEA & 2.01 & 2.55 & $44.1 \%$ \\
BDO-PU & MDI & PPG-2000 & BDO & TEA & 1.97 & 2.09 & $48.5 \%$ \\
HDO-PU & MDI & PPG-2000 & HDO & TEA & 1.53 & 1.82 & $45.7 \%$ \\
PDO-PU & MDI & PPG-2000 & PDO & TEA & 2.13 & 2.93 & $42.1 \%$ \\
MPO-PU & MDI & PPG-2000 & MPO & TEA & 1.89 & 2.62 & $41.9 \%$ \\
NPG-PU & MDI & PPG-2000 & NPG & TEA & 2.47 & 3.66 & $40.3 \%$ \\
TEA-PU & MDI & PPG-2000 & BDO & TEA & 1.97 & 2.09 & $48.5 \%$ \\
HTO-PU & MDI & PPG-2000 & BDO & HTO & 1.73 & 1.75 & $49.7 \%$ \\
GLY-PU & MDI & PPG-2000 & BDO & GLY & 2.11 & 2.55 & $45.3 \%$ \\
\hline
\end{tabular}

TEA-PU, HTO-PU, and GLY-PU, respectively. The formulations of the PUEs are shown in Table 1 and the molar ratio of isocyanate, polyhydric alcohols, the chain extender, and the crosslinking agent was $2.05: 1: 0.5: 0.5$.

The FT-IR spectra of EG-PU, BDO-PU, and HDO-PU are shown in Fig. 3(a). The peaks $3280-3340 \mathrm{~cm}^{-1}$ was attributed to the stretching of the $\mathrm{N}-\mathrm{H}$ group. The strong absorption peaks at 1100 and $1224 \mathrm{~cm}^{-1}$ corresponded to the $\mathrm{C}-\mathrm{O}-\mathrm{C}$ stretching vibration of soft polyol segments. ${ }^{(27,28)}$ The $2980 \mathrm{~cm}^{-1}\left(\mathrm{C}-\mathrm{H}\right.$ stretching in $\left.-\mathrm{CH}_{2}-\right), 2862 \mathrm{~cm}^{-1}(\mathrm{C}-\mathrm{H}$ stretching in $\left.-\mathrm{CH}_{3}\right), 1733 \mathrm{~cm}^{-1}(\mathrm{C}=\mathrm{O})$, and $1539 \mathrm{~cm}^{-1}(\mathrm{~N}-\mathrm{H}$ bending) peaks were characteristic peaks. The disappearance of the isocyanate group (-NCO) stretching band at $2260 \mathrm{~cm}^{-1}$ confirmed the formation of PUEs, which indicates that there is no residual -NCO group. The FT-IR spectra of PDO-PU, MPO-PU, and NPG-PU in Fig. 3(b) exhibited the bands of typical PUEs. Figure 3(c) shows the FT-IR spectra of GLY-PU, HTO-PU, and TEA-PU, which show the characteristic peaks of PUEs.

To study the degree of microphase separation, the amount of hydrogen bonding association (HBA) of the carbonyl group was calculated. The stretching vibrations of $\mathrm{C}=\mathrm{O}$ at 1700 and $1730 \mathrm{~cm}^{-1}$ are due to the presence of hydrogen-bonded urea carbonyls and free urethane carbonyls, respectively. ${ }^{(29,30)}$ The hydrogen urea carbonyls only exist in the hard segments, 


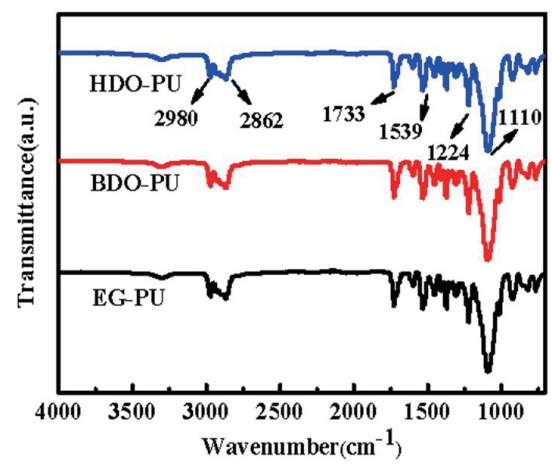

(a)

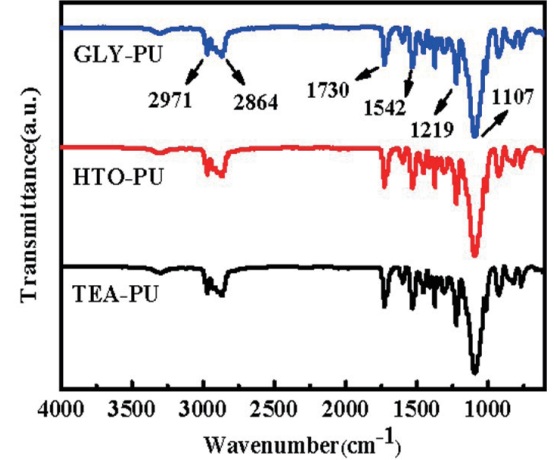

(c)

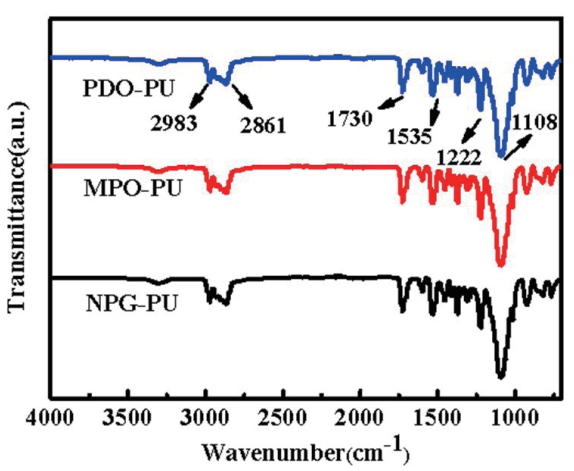

(b)

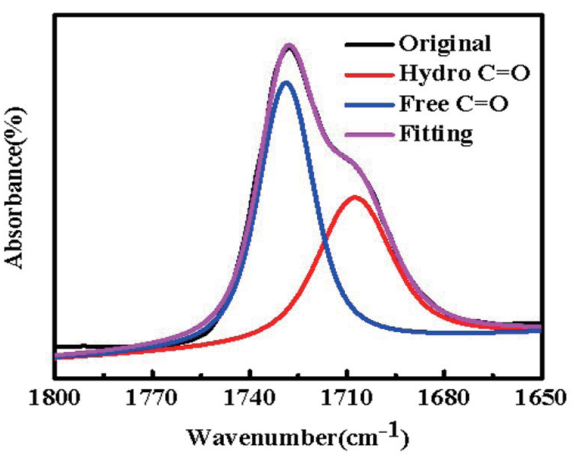

(d)

Fig. 3. (Color online) FT-IR spectra of (a) HDO-PU, BDO-PU, and EG-PU; (b) PDO-PU, MPO-PU, and NPG-PU; (c) GLY-PU, HTO-PU, and TEA-PU; (d) fitting curve of $\mathrm{C}=\mathrm{O}$ at about $1730 \mathrm{~cm}^{-1}$.

and the free urethane carbonyls are only dispersed in the soft segments. For example, an enlarged view of the EG-PU curve in Fig. 3(a) from 1650 to $1800 \mathrm{~cm}^{-1}$ is shown in Fig. 3(d). The hydrogen-bonded and free carbonyl stretching bands were observed at 1700 and $1730 \mathrm{~cm}^{-1}$, respectively. The HBA value was calculated by

$$
H B A=A_{1700} /\left(A_{1700}+A_{1730}\right) \times 100 \%,
$$

where $A_{1700}$ is the peak area of the hydrogen-bonded urea carbonyl at $1700 \mathrm{~cm}^{-1}$ and $A_{1730}$ is the peak area of the free urea carbonyl at $1730 \mathrm{~cm}^{-1}$. All the $A_{1700}, A_{1730}$, and HBA values are summarized in Table 1. The amount of hydrogen bonding was correlated with the aggregation of hard segments. The HBA value of NPG-PU (40.3\%) was lower than that of the other samples, which indicates that the aggregation of hard segments for NPG-PU was the lowest among all samples.

\subsection{Mechanical properties}

To investigate the mechanical properties of PUEs with different lengths of chain extenders, the hardness and compression modulus of EG-PU, BDO-PU, and HDO-PU were obtained as 
shown in Fig. 4(a). The hardness values of EG-PU, BDO-PU, and HDO-PU were 28, 34, and 27 , respectively. The compression moduli were 1.20, 1.52, and $1.21 \mathrm{MPa}$, respectively. Among the three groups of samples, BDO-PU had the best mechanical properties. Compared with the length of BDO, the length of EG was smaller and it was more difficult for EG-PU to form ordered hard segments. This is because the smaller hard-segment regions were easily dispersed in the soft-segment matrix, affecting the degree of microphase separation. When the molecular chain was longer, such as for HDO, it was easier for the molecular chain to slip, making the material softer. To assess the mechanical properties of different substituent groups, repeated measurements were performed. As shown in Fig. 4(b), the hardness and compression modulus of PDO-PU were the highest among the three samples, indicating that increasing the number of side chains of the chain extender deteriorated the mechanical properties of PUEs.

The kind of cross-linking agent has a greater effect on the cross-link density than the other factors. Figure 4(c) shows the mechanical properties of TEA-PU, HTO-PU, and GLY-PU. Their hardness values were 34,48 , and 41 , and their compression moduli were $1.53,4.14$, and 2.91 MPa, respectively. The mechanical properties of TEA-PU were inferior to those of the other two samples. This is because the distance between the hydroxyl groups in the structure of TEA was the longest among them, which inhibited the accumulation of hard segments and the formation of a tight cross-linked structure.

\subsection{Crystal property}

To observe the aggregation of hard segments, the X-ray diffraction (XRD) patterns of EGPU, BDO-PU, and HDO-PU were obtained, as shown in Fig. 5(a). The broad diffraction peaks at about $20^{\circ}$ were attributed to the amorphous structure of the materials. The dispersion peaks also represented the aggregation structure of hard segments. The intensity of the BDO-PU peak appearing at $20^{\circ}$ was higher than that of EG-PU. This is because the small length and volume of EG decreased the aggregation degree of EG-PU. The intensity of the HDO-PU peak appearing at $20^{\circ}$ was less than that of BDO-PU owing to the long molecular chain. This observation was consistent with the HBA values and the hardness and compression modulus results. The

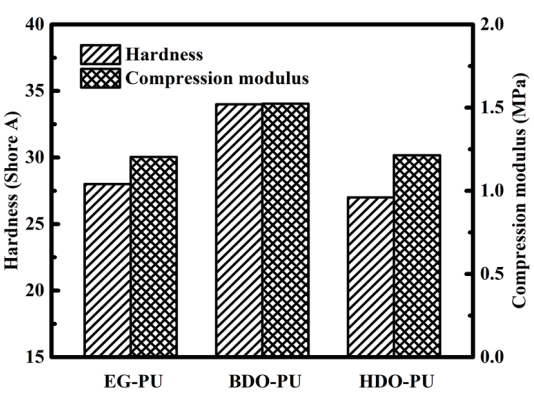

(a)

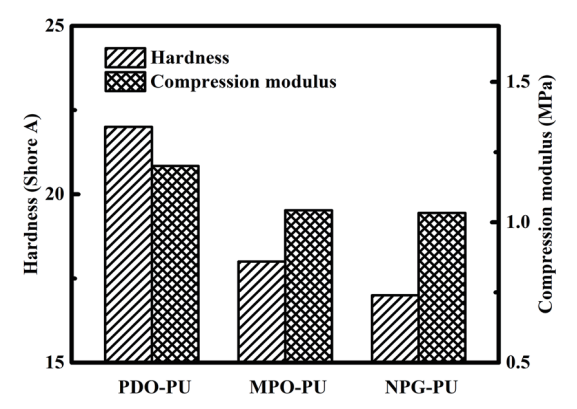

(b)

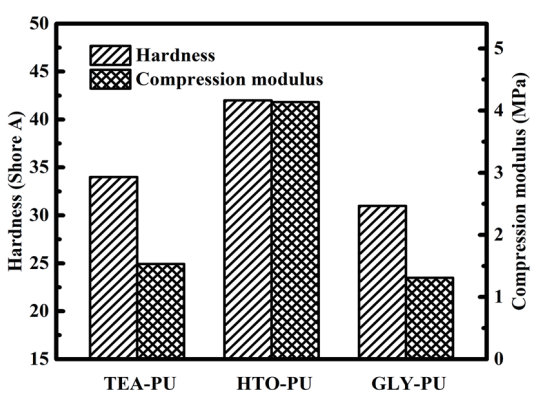

(c)

Fig. 4. (a) Hardness and compression modulus graph of EG-PU, BDO-PU, and HDO-PU. (b) Hardness and compression modulus graph of PDO-PU, MPO-PU, and NPG-PU. (c) Hardness and compression modulus graph of TEA-PU, HTO-PU, and GLY-PU. 


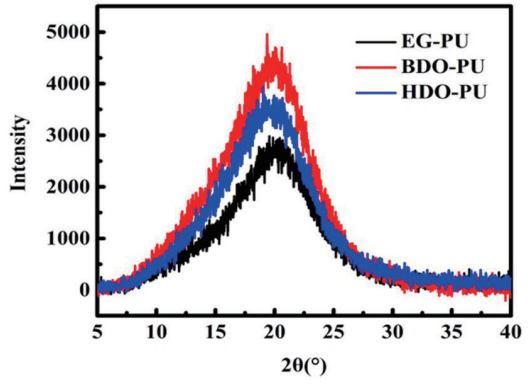

(a)

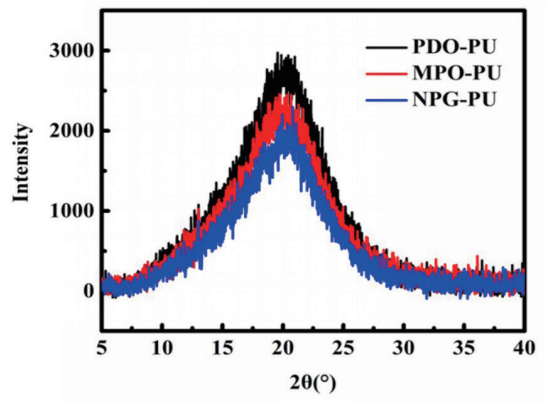

(b)

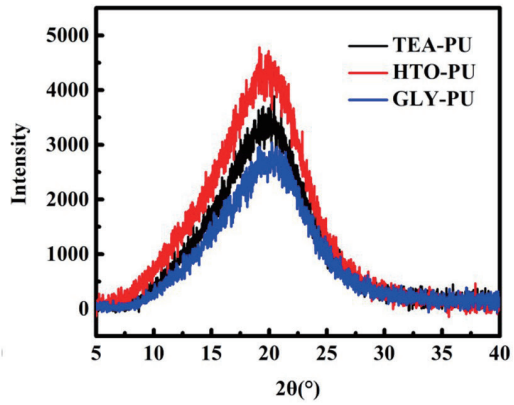

(c)

Fig. 5. (Color online) (a) XRD patterns of EG-PU, BDO-PU, and HDO-PU. (b) XRD patterns of PDO-PU, MPOPU, and NPG-PU. (c) XRD patterns of TEA-PU, HTO-PU, and GLY-PU.

aggregation degree of PDO-PU was also the highest among PDO-PU, MPO-PU, and NPG-PU as shown in Fig. 5(b). Taken together, these results suggest that there is an association between the hardness and the aggregation of hard segments.

Figure 5(c) shows the XRD analysis results of PUEs with different cross-linking agents. It can be seen that the hard segment aggregation ability of HTO-PU is greatest, which is consistent with the data of its hydrogen bond strength and mechanical properties. Although there is no sharp crystal peak, the dispersion peak also represents the aggregation structure of hard segments to some extent.

\subsection{Damping property}

Polymers with different structures have different glass transition temperatures $\left(T_{g}\right)$ and damping properties. Figure 6(a) shows $\tan \delta$ as a function of the temperature of EG-PU, BDOPU, and HDO-PU. The $T_{g}$ values of EG-PU, BDO-PU, and HDO-PU were $-17.0,-20.2$, and $-17.2{ }^{\circ} \mathrm{C}$, respectively. It can be seen from Fig. 6(a) that the highest value of $\tan \delta$ was 1.42 for EG-PU. At the vibration isolation test temperature of $20^{\circ} \mathrm{C}$, the order of $\tan \delta$ values was EG$\mathrm{PU}>\mathrm{BDO}-\mathrm{PU}>\mathrm{HDO}-\mathrm{PU}$, which indicates that EG-PU may have better vibration isolation performance than BDO-PU and HDO-PU. $\tan \delta$ as a function of the temperature for PDO-PU, MPO-PU, and NPG-PU is shown in Fig. 6(b). $\tan \delta$ for PDO-PU was 1.27 at $-17.7^{\circ} \mathrm{C} . \tan \delta$ for MPO-PU was 0.85 at $-22.9^{\circ} \mathrm{C}$. $\tan \delta$ for NPG-PU was 1.39 at $-24.0^{\circ} \mathrm{C}$. The order of $\tan \delta$ values was MPO-PU > NPG-PU > PDO-PU at the vibration isolation test temperature of $20{ }^{\circ} \mathrm{C}$. The steric hindrance effect from the side group of the chain extender was negative for the motion of the molecular chain, which may have resulted in the damping factors of MPO-PU and NPG-PU both being lower than that of PDO-PU. From Fig. 6(c), $\tan \delta$ for TEA-PU was 1.27 at $-20.40{ }^{\circ} \mathrm{C} . \tan \delta$ for HTO-PU was 1.20 at $-18.43{ }^{\circ} \mathrm{C}$. $\tan \delta$ for GLY-PU was 1.29 at $-15.29{ }^{\circ} \mathrm{C}$. At the vibration isolation test temperature of $20^{\circ} \mathrm{C}$, the order of $\tan \delta$ values was GLY-PU > TEAPU $>$ HTO-PU. The compact spatial structure of GLY-PU provides its damping property. 


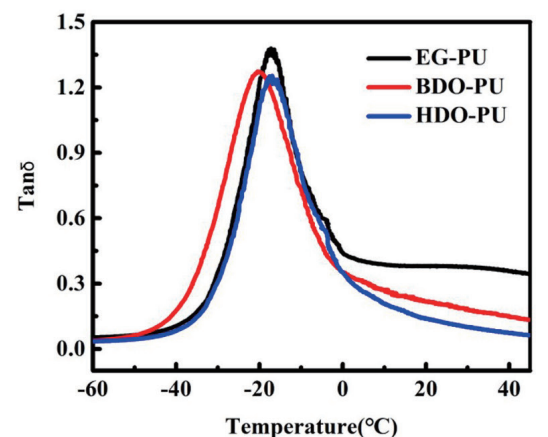

(a)

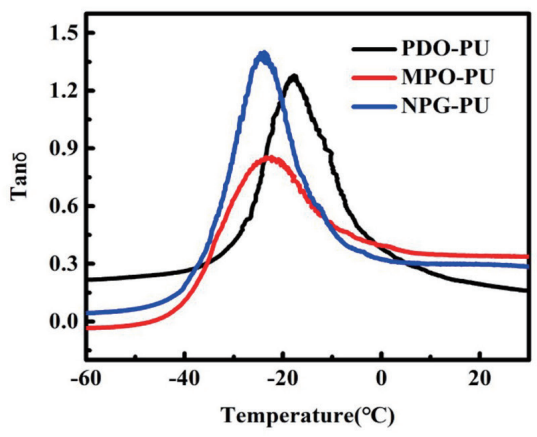

(b)

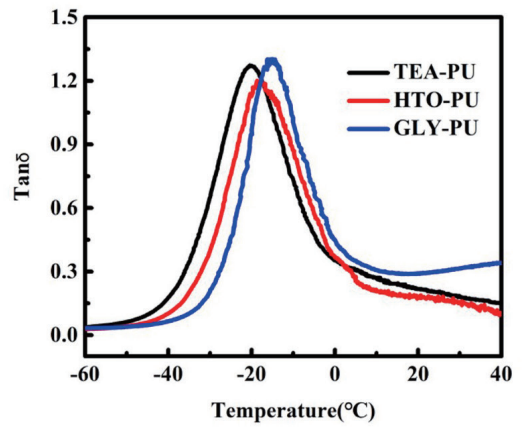

(c)

Fig. 6. (Color online) (a) Dependence of $\tan \delta$ on temperature of EG-PU, BDO-PU, and HDO-PU. (b) Dependence of $\tan \delta$ on temperature of PDO-PU, MPO-PU, and NPG-PU. (c) Dependence of $\tan \delta$ on temperature of TEA-PU, HTO-PU, and GLY-PU.

\subsection{Vibration isolation property}

The vibration isolation performance of PUEs with chain extenders of different lengths is shown in Fig. 7(a). In the range of $150-800 \mathrm{~Hz}$, EG-PU had the strongest vibration isolation effect. PUEs are typical viscoelastic materials. When PUEs are subjected to external forces, their molecular chain slips and deforms giving them excellent viscoelastic performance at the macro level. When this force is removed, part of the molecule chain slowly returns to its original position, whereas the other part of the chain cannot recover because of the energy transferred by the force. For the three samples, the chain extender of EG had the minimum number of carbon atoms and the lowest degree of hard-segment aggregation, so it was most likely to deform when the PUE was subjected to external forces. Compared with BDO-PU, HDO-PU has better flexibility of the molecular chain. Therefore, the molecular chain was more likely to deform and slip to absorb and consume more energy, so the vibration isolation performance was better than that of BDO-PU.

Figure 7(b) shows the vibration isolation performance of PUEs with different substituent groups in the range of $150-800 \mathrm{~Hz}$. The vibration isolation effect of PDO-PU was clearly lower than those of MPO-PU and NPG-PU, which indicated that the vibration isolation performance improved with increasing number of substituent groups. PDO-PU, MPO-PU, and NPG-PU have the same length of the main chain; however, the substituent groups decreased the degree of hard-segment aggregation because of the steric hindrance effect and the decreased strength of the hydrogen bonds.

The vibration isolation performance of polyurethane with cross-linking agents of different structures is shown in Fig. 7(c). In the range of $150-800 \mathrm{~Hz}$, the vibration isolation intensities of TEA-PU, HTO-PU, and GLY-PU reached more than $10 \mathrm{~dB}$, and the vibration isolation effect of GLY-PU was the strongest. Among TEA and HTO, GLY has the fewest carbon atoms and the most irregular structure, which resulted in the best vibration isolation performance. The molecular chain of HTO-PU was not easily deformed when subjected to external forces, so the vibration isolation effect was the weakest. 


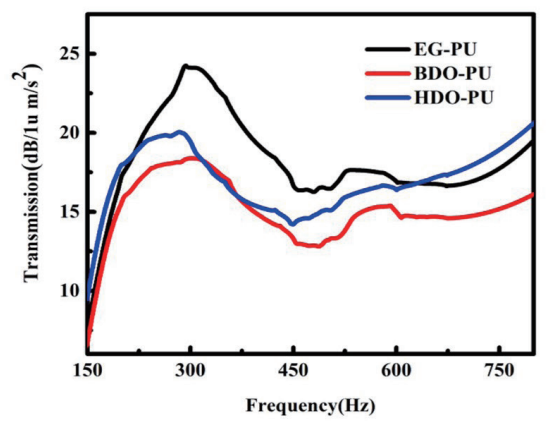

(a)

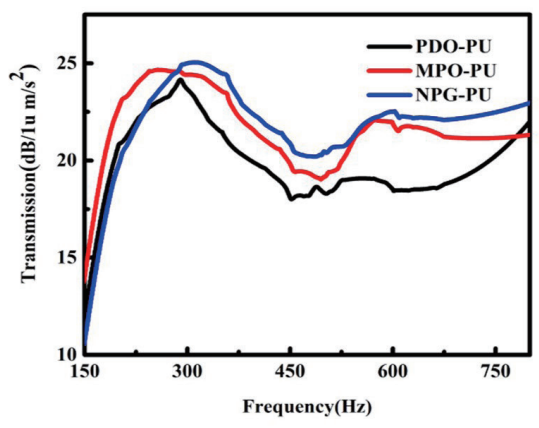

(b)

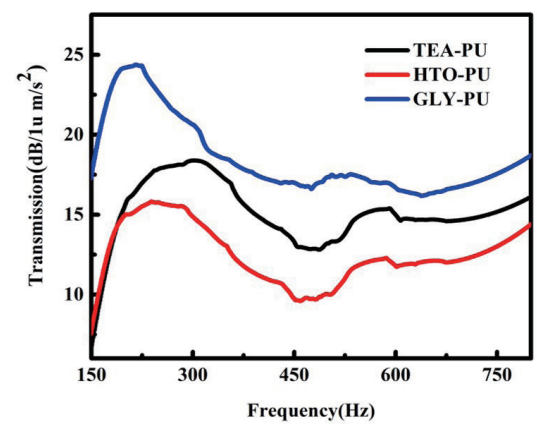

(c)

Fig. 7. (Color online) (a) Vibration isolation curves of EG-PU, BDO-PU, and HDO-PU. (b) Vibration isolation curves of PDO-PU, MPO-PU, and NPG-PU. (c) Vibration isolation curves of TEA-PU, HTO-PU, and GLY-PU.

\section{Conclusions}

PUEs with different chain extenders and cross-linkers were synthesized. A shorter molecular chain length of the chain extender improved the damping performance and vibration isolation performance. With increasing number of side groups of the chain extender, the volume of space occupied increased and the damping and vibration isolation properties were improved. The evenness of chain extender will affect the degree of hydrogen bonding in PUE materials. Among the three commonly used cross-linkers, the sample of PUE prepared using GLY had the best vibration isolation and damping performance. A more irregular structure of the crosslinkers resulted in better vibration isolation performance of the PUEs.

\section{Acknowledgments}

This work was financially supported by State Key Laboratory of Marine Coatings (KY11000180016), National Natural Science Foundation of China (Grant No. 51803041), and the Fundamental Research Funds for the Central Universities (3072019CFM1001, HEUCFJ181006).

\section{References}

1 L. Li, L. Y. Tan, L. Kong, D. Wang, and H. B. Yang: Mech. Syst. Signal Proc. 100 (2018) 360. https://doi. org/10.1016/j.ymssp.2017.07.029

2 J. X. Fei, B. Lin, S. Yan, M. Ding, J. L. Xiao, J. Zhang, X. F. Zhang, C. H. Ji, and T. Y. Sui: J. Sound Vibr. 410 (2017) 49. https://doi.org/10.1016/j.jsv.2017.08.033

3 P. F. Cao, B. R. Li, T. Hong, J. Townsend, Z. Qiang, K. Y. Xing, K. D. Vogiatzis, Y. Y. Wang, J. W. Mays, A. P. Sokolov, and T. Saito: Adv. Funct. Mater. 28 (2018) 1800741. https://doi.org/10.1002/adfm.201800741

4 M. Altan, M. Bayraktar, and B. Yavuz: Int. J. Adv. Manuf. Technol. 86 (2016) 2119. https://doi.org/10.1007/ s00170-015-8259-8

5 X. Chen, W. Wang, and C. Jiao: J. Hazard. Mater. 331 (2017) 257. https://doi.org/10.1016/j.jhazmat.2017.02.011

6 H. Li, J. T. Sun, C. Wang, S. L. Liu, D. Yuan, X. Zhou, J. Tan, L. Stubbs, and C. B. He: ACS Sustainable Chem. Eng. 5 (2017) 7942. https://doi.org/10.1021/acssuschemeng.7b01481

7 D. Lei, Y. Yang, Z. H. Liu, S. Chen, B. Y. Song, A. Shen, B. Q. Yang, S. Li, Z. Z. Yuan, Q. Qi, L. J. Sun, Y. F. Guo, H. Zuo, S. X. Huang, Q. Yang, X. M. Mo, C. L. He, B. Zhu, E. M. Jeffries, F. L. Qing, X. F. Ye, Q. Zhao, and Z. W. You: Mater. Horiz. 6 (2019) 394. https://doi.org/10.1039/c8mh00937f 
8 Q. Xia, L. Chen, Y. Zhu, Z. Shao, and M. Guo: J. Mat. Chem. B 7 (2019) 1734. https://doi.org/10.1039/ c8tb02585a

9 P. Alagi, R. Ghorpade, Y. J. Choi, U. Patil, I. Kim, J. H. Baik, and S. C. Hong: ACS Sustainable Chem. Eng. 5 (2017) 3871. https://doi.org/10.1021/acssuschemeng.6b03046

10 R. Wang, X. Song, T. Xiang, Q. Liu, B. Su, W. Zhao, and C. Zhao: Carbohydr. Polym. 168 (2017) 310. https:// doi.org/10.1016/j.carbpol.2017.03.092

11 S. Mohd Norhisham, T. I. Tuan Noor Maznee, H. Nurul Ain, P. P. Kosheela Devi, A. Srihanum, M. N. Norhayati, S. K. Yeong, A. H. Hazimah, C. M. Schiffman, A. Sendijarevic, V. Sendijarevic, and I. Sendijarevic: Int. J. Adhes. Adhes. 73 (2017) 38. https://doi.org/10.1016/j.ijadhadh.2016.10.012

12 S. Sahoo, H. Kalita, S. Mohanty, and S. K. Nayak: Macromol. Res. 25 (2017) 772. https://doi.org/10.1007/ s13233-017-5080-2

13 M. B. Karimi, G. Khanbabaei, and G. M. M. Sadeghi: J. Membr. Sci. 527 (2017) 198. https://doi.org/10.1016/ j.memsci.2016.12.008

14 R. Poreba, M. Spirkova, L. Brozova, N. Lazic, J. Pavlicevic, and A. Strachota: J. Appl. Polym. Sci. 127 (2013) 329. https://doi.org/10.1002/app.37895

15 X. Chen, W. Wang, S. Li, and C. Jiao: J. Hazard. Mater. 324 (2017) 789. https://doi.org/10.1016/ j.jhazmat.2016.11.065

16 F. Naz, M. Zuber, K. Mehmood Zia, M. Salman, J. Chakraborty, I. Nath, and F. Verpoort: Carbohydr. Polym. 200 (2018) 54. https://doi.org/10.1016/j.carbpol.2018.07.076

17 P. J. Taroni, G. Santagiuliana, K. N. Wan, P. Calado, M. T. Qiu, H. Zhang, N. M. Pugno, M. Palma, N. Stingelin-Stutzman, M. Heeney, O. Fenwick, M. Baxendale, and E. Bilotti: Adv. Funct. Mater. 28 (2018) 1704285. https://doi.org/10.1002/adfm.201704285

18 N. Jiang, G. F. Li, W. L. Che, D. X. Zhu, Z. M. Su, and M. R. Bryce: J. Mater. Chem. C 6 (2018) 11287. https:// doi.org/10.1039/c8tc04250k

19 Z. Q. Huang, X. T. Hu, C. Liu, L. C. Tan, and Y. W. Chen: Adv. Funct. Mater. 27 (2017) 1703061. https://doi. org/10.1002/adfm.201703061

20 P. N. Zhang, L. Li, J. J. Zhang, and C. Gao: Int. J. Appl. Electromagn. Mech. 58 (2018) 261. https://doi. org/10.3233/Jae-180050

21 J. Culin: Polimery 61 (2016) 159. https://doi.org/10.14314/polimery.2016.159

22 H. Endo, S. Kato, M. Watanabe, T. Kikuchi, M. Kawai, and T. Mitsumata: Polymers (Basel) 10 (2018) 104. https://doi.org/10.3390/polym10010104

23 F. Ebrahimi and M. R. Barati: Compo. Struct. 159 (2017) 433. https://doi.org/10.1016/j.compstruct.2016.09.092

24 J. Fu, P. D. Li, Y. Wang, G. Y. Liao, and M. Yu: Smart Mater. Struct. 25 (2016). https://doi.org/10.1088/0964$1726 / 25 / 3 / 035030$

25 A. Calabrese, G. Serino, S. Strano, and M. Terzo: Meccanica 50 (2015) 2201. https://doi.org/10.1007/s11012015-0155-7

26 E. Choi, H. Youn, K. Park, and J. S. Jeon: Eng. Struct. 132 (2017) 372. https://doi.org/10.1016/ j.engstruct.2016.11.050

27 H. Daemi, M. Barikani, and M. Barmar: Carbohydr. Polym. 92 (2013) 490. https://doi.org/10.1016/ j.carbpol.2012.09.046

28 X. Liu, K. Xu, H. Liu, H. L. Cai, J. X. Su, Z. E. Fu, Y. Guo, and M. C. Chen: Prog. Org. Coat. 72 (2011) 612. https://doi.org/10.1016/j.porgcoat.2011.07.002

29 J. Liao, Z. Luo, Y. Zhang, X. Zhang, J. Cheng, and Q. Wu: New J. Chem. 38 (2014) 2522. https://doi. org/10.1039/c3nj01647a

30 T. Travinskaya, Y. Savelyev, and E. Mishchuk: Polym. Degrad. Stab. 101 (2014) 102. https://doi.org/10.1016/ j.polymdegradstab.2013.12.006 